\title{
Topographical and hydrological effects on meso-scale vegetation in desert steppe, Mongolia
}

\author{
Batdelger GANTSETSEG ${ }^{1,2 *}$, Masahide ISHIZUKA ${ }^{2}$, Yasunori KUROSAKI ${ }^{3}$, \\ Masao MIKAMI ${ }^{4}$ \\ ${ }^{1}$ Information and Research Institute of Meteorology, Hydrology and Environment, Ulaanbaatar 15160, Mongolia; \\ ${ }^{2}$ Faculty of Engineering, Kagawa University, Takamatsu 761-0396, Japan; \\ ${ }^{3}$ Arid Land Research Center, Tottori University, Tottori 680-0001, Japan; \\ ${ }^{4}$ Japan Meteorological Business Support Center, Tokyo 101-0054, Japan
}

\begin{abstract}
This study investigated the seasonal variations of the normalized difference vegetation index (NDVI) and its relationships with climatic variables and topography in a small-scale $(20 \mathrm{~km} \times 20 \mathrm{~km})$ area (i.e., Tsogt-Ovoo village) within the desert steppe zone of Mongolia using in-situ observed climate data and satellite remote sensing data. We found that the topography is very important for vegetation growth in the desert steppe although the summer precipitation is the constraining factor. The unexpectedly high NDVI (up to 0.56), as well as the high aboveground biomass, in the valley bottom was primarily resulted from the topography-modulated redistribution of overland flow after relatively heavy precipitation events during the growing season. This makes the valley bottoms in desert steppes not only reliable feeding resources for livestock but also heavens for wild lives. But, the detected large standard deviation of annual maximum NDVI (NDVI $I_{\max }$ ) from 2000 to 2013 in the valley bottom in response to rather variable precipitation implies that the valley bottoms under desert steppe climates are more vulnerable to climatic change.
\end{abstract}

Keywords: topography; climatic variable; desert valley; vegetation; soil moisture; Terra-MODIS NDVI

Citation: Batdelger GANTSETSEG, Masahide ISHIZUKA, Yasunori KUROSAKI, Masao MIKAMI. 2017. Topographical and hydrological effects on meso-scale vegetation in desert steppe, Mongolia. Journal of Arid Land, 9(1): 132-142. doi: $10.1007 / \mathrm{s} 40333-016-0090-\mathrm{z}$

\section{Introduction}

The vegetation of an ecosystem not only provides essential ecological, economic, and social products and services but also plays an important role in land-air coupling processes (Ma et al., 2010; Ignatavičius et al., 2013). Consequently, the coupling relationships between climate variables and vegetation parameters have been extensively investigated (Miyazaki et al., 2004; Li et al., 2007; Munkhtsetseg et al., 2007; Yamanaka et al., 2007). The relevant investigations have recently been further advanced and expanded through using satellite remote sensing data (Yu et al., 2003; Zhang et al., 2003; Pettorelli et al., 2005; Zhu et al., 2013). Among the relevant investigations, land cover analysis using satellite remote sensing data is a well-developed technique for calculating land cover fractions within a pixel of the remotely-sensed data (Ridd, 1995; Yue et al., 2006; Weng and Lu, 2009; Mayes et al., 2015). Calculating land cover fractions has been widely adopted to explore the vegetation responses to climate variations in hyper-arid and semi-arid areas, especially to precipitation variations (Fensholt et al., 2012; Yin et al., 2012;

*Corresponding author: Batdelger GANTSETSEG (E-mail: gantsetseg2015@gmail.com)

Received 2015-08-20; revised 2016-06-24; accepted 2016-07-29

(C) Xinjiang Institute of Ecology and Geography, Chinese Academy of Sciences, Science Press and Springer-Verlag Berlin Heidelberg 2017 
Zhao et al., 2015). The normalized difference vegetation index (NDVI) has been widely used for understanding the dynamic relationships between vegetation parameters and climate variables (Guo et al., 2014; Jarlan et al., 2014).

The instrumental records show that the temperature has been steadily rising since 1940 in Mongolia and the precipitation has no rising trend at all (Dagvadorj et al., 2014). This simply implies that the effective soil moisture might have been declining due to rising temperature via evaporation enhancement at large spatial scales. However, the effective soil moisture and the associated vegetation growth at small spatial scales might have been somewhat independent from the large-scale patterns. In fact, it was reported that local climate and local topography are often very important in modulating the effective soil moisture and the associated vegetation growth (Wang et al., 2001, 2003; Ni, 2003; Zhou et al., 2003; Miyazaki et al., 2004; Zhang et al., 2005; Cheng et al., 2011; Li and Guo, 2012; Vandandorj et al., 2015).

The Mongolian desert steppe is presently facing severe environmental challenges including desertification and overgrazing (Chuluun and Ojima, 2002; Stumpp et al., 2005; Wang et al., 2006; Lu et al., 2009; Zhang et al., 2009). The desert steppe occupies about 23\% of the total territory in Mongolia (Iwasaki, 2006; Johnson et al., 2006; Vandandorj et al., 2015). The vegetation productivity level is rather low in the desert steppe, but the economic significance and ecological importance are not negligible (Saizen et al., 2010). Existing studies have explored the small-scale relationships between the vegetation productivity levels and the controlling or modulating factors in other arid and semi-arid areas. For example, Li and Guo (2014) reported that vegetation growth in semi-arid areas is controlled by such factors as soil moisture, soil temperature, soil types and others. Their study ( $\mathrm{Li}$ and Guo, 2014) stressed that topography can be one of the most important factors in modulating vegetation growth in semi-arid areas. Our study focused on a small-scale $(20 \mathrm{~km} \times 20 \mathrm{~km})$ area (i.e., Tsogt-Ovoo village) within the desert steppe zone of Mongolia and attempted to explore the topographic influence on vegetation growth using in-situ observed climate data and satellite remote sensing data.

\section{Materials and methods}

\subsection{Site description}

The observation site is situated within Tsogt-Ovoo soum $\left(44^{\circ} 23^{\prime} 04^{\prime \prime} \mathrm{N}, 105^{\circ} 16^{\prime} 60^{\prime \prime} \mathrm{E} ; 1237 \mathrm{~m}\right.$ a.s.1.), a village in Umnugovi aimag (a province) in the northern part of the Gobi Desert, Mongolia. The valley, where Tsogt-Ovoo soum (the village) is situated, runs approximately from northwest to southeast with a width of about $10 \mathrm{~km}$ (Fig. 1). The observation site is on the northern slope of the valley. The natural vegetation around the site was categorized as desert steppe (Yunatov, 1976) and the vegetation coverage ranged from 5\% to $15 \%$ in July 2011 (Ishizuka et al., 2012). The plant communities were dominated by Anabasis brevifolia, Reaumuria soongarica, Salsola passerina, Nitraria sibirica, and Kalidium cuspidatum (Ishizuka et al., 2012).

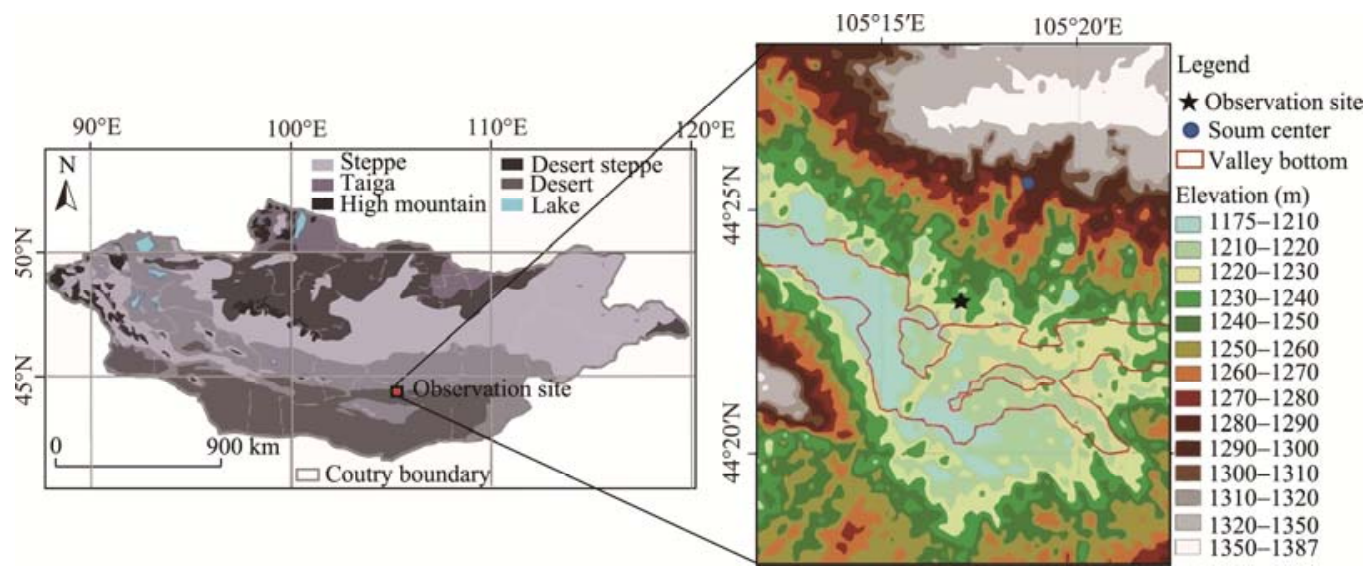

Fig. 1 Location and topography of the observation site in Tsogt-Ovoo soum, Mongolia 


\subsection{Measurements and vegetation data}

Long-term climatic data were collected from the Tsogt-Ovoo meteorological station, a surface synoptic observatory operated by the National Agency for Meteorology and Environmental Monitoring of Mongolia. The station is located approximately $5.3 \mathrm{~km}$ north of the center of the observation site. The precipitation was measured twice a day using a glass rain gauge and the snow depth was measured at three positions inside the meteorological station once every morning during the snow-covering season. Air temperature and humidity were measured using HMP-1550-10 (Vaisala Corp., Helsinki, Finland) at $1.98 \mathrm{~m}$ above the ground. The soil temperature and soil moisture were measured at the depths of 1.0, 2.5, 5.0, 10.0, 15.0, 20.0, 30.0, and $50.0 \mathrm{~cm}$ using platinum sensors (Pt100, Climatec Inc., Toshima, Tokyo, Japan) and amplitude domain reflectometry soil moisture sensors (The taProbe ML2x, Delta-T Devices Ltd., Burwell, Cambridge, UK), respectively. A data logger (CR1000-XT, Campbell Scientific Inc., North Logan, UT, USA) was used to record the data.

The Terra moderate resolution imaging spectroradiometer (Terra-MODIS) NDVI, which has 16-day composite data for the entire country of Mongolia between 2000 and 2013, was used in this study and the Terra-MODIS image has a fine resolution $(250 \mathrm{~m})$. The aboveground biomass in 2012 and 2013 were in-situ measured by the Information and Research Institute of Meteorology, Hydrology and Environment, Mongolia. The measurements were conducted in a 50 $\mathrm{m} \times 50 \mathrm{~m}$ fenced pasture on the $4^{\text {th }}, 14^{\text {th }}$ and $24^{\text {th }}$ of each month during the growing season (June to September).

\subsection{Statistical analysis}

To investigate the topographic effects on vegetation coverage, we traced the variations in the vegetation coverage in the valley bottom and in the uplands from 2000 to 2013 using standard deviation (SD). To identify the topographic positions with the largest vegetation variability, we calculated the distribution of the annual maximum NDVI's SD between 2000 and 2013 using Equation 1.

$$
S D=\frac{1}{N} \sum_{i=1}^{N}\left(x_{i}-\mu\right)^{2} .
$$

Where $N$ is the number of years; $x_{i}$ is the maximum NDVI in the $i^{\text {th }}$ year; and $\mu$ is the mean annual maximum NDVI between 2000 and 2013.

The trends in NDVI variations were detected via the nonparametric Mann-Kendall test and the changing rates were evaluated based on Sen's slope. The Mann-Kendall test has been used to detect the trend of normally- or abnormally-distributed time series in meteorological variables (Sayemuzzaman and Jha, 2014) and also in ecological variable. The Mann-Kendall test statistic $(S)$ is computed as,

$$
\begin{gathered}
S=\sum_{k-1}^{n-1} \sum_{j=k+1}^{n} \operatorname{sign}\left(N D V I_{j}-N D V I_{k}\right) . \\
\operatorname{sign}\left(N D V I_{j}-N D V I_{k}\right)=\left\{\begin{array}{c}
1, \text { if }\left(N D V I_{j}-N D V I_{k}\right)>0 \\
0, \text { if }\left(N D V I_{j}-N D V I_{k}\right)=0 . \\
-1, \text { if }\left(N D V I_{j}-N D V I_{k}\right)<0
\end{array}\right.
\end{gathered}
$$

Where $n$ is the data length; $N D V I_{j}$ and $N D V I_{k}$ are the annual NDVI in year $j$ and $k(j>k)$, respectively.

The variance of $S$ is defined as,

$$
\operatorname{Var}(S)=\frac{n(n-1)(2 n+5)}{18} .
$$

The test statistic $Z$ is calculated as, 


$$
Z=\left\{\begin{array}{cl}
\frac{S+1}{\sqrt{\operatorname{Var}(S)}}, & S>0 \\
0, & S=0 . \\
\frac{S-1}{\sqrt{\operatorname{Var}(S)}}, & S<0
\end{array} .\right.
$$

In this study, the statistical trend of mean NDVI was evaluated using the $Z$ value. A negative $Z$ value indicates a downward trend, a positive $Z$ value shows an upward trend, and a zero $Z$ value means neither detectable downward trend nor detectable upward trend. The slope of the trend (i.e., amount of change per year) was computed using Sen's nonparametric method. Time series data $f(t)$ with a continuous monotonic increasing or decreasing trend can be expressed as,

$$
f(t)=Q_{t}+\mathrm{B} .
$$

Where $Q_{t}$ is a slope and B is a constant. $Q_{t}$ is estimated by Equation 7.

$$
Q_{t}=\frac{N D V I_{j}-N D V I_{k}}{j-k}, i=1,2, \ldots, N, j>k .
$$

Where $j$ and $k$ are the year number. Sen's estimator of slope $Q_{t}$ is the median of these $N$ values of $Q_{t}$, calculated as follows:

$$
Q=\left\{\begin{array}{ll}
Q_{\frac{N+1}{2}}, & \text { if } N \text { is odd } \\
\frac{1}{2}\left(Q_{N}+Q_{N+1}\right), & \text { if } N \text { is even }
\end{array} .\right.
$$

Where $N=n(n-1) / 2$ is the number of calculated slopes; and $n$ is the length of data (14 in this study).

\section{Results and discussion}

\subsection{Hydrological characteristics}

The annual precipitation at the meteorological station was $116.0 \mathrm{~mm}$ in 2012 (wet year) and 60.1 $\mathrm{mm}$ in 2013 (dry year). As shown in Figure 2a, 92\% of the total precipitation (106.6 mm) fell during the rainy season from May to September in 2012 and $89 \%$ of the total precipitation (53.4 $\mathrm{mm}$ ) fell during the rainy season in 2013. The maximum monthly precipitation in 2012 was observed in July (49.4 mm), whereas the maximum in 2013 was observed in June $(22.0 \mathrm{~mm})$. The total precipitation of April and May were small in both $2012(3.4 \mathrm{~mm})$ and $2013(1.3 \mathrm{~mm})$.

The study area was normally covered by snow from preceding mid-November to succeeding early March. The largest snow depth occurred in January and the number of snow-covered days was usually less than 50 days (Jambaajamts, 1989). A large amount of snow was observed in the 2012/2013 winter from November of 2012 to February of 2013 (Fig. 2b) and a total of 57 snow-covered days was recorded from 20 December of 2012 to 18 February of 2013. Because the soil temperature was consecutively below $0^{\circ} \mathrm{C}$ from proceeding early November to succeeding early March (Fig. 2b), the observed decrease in snow depth was speculated to be caused by sublimation rather than melting.

The soil moisture during the late July to September in 2012 was higher than that during the same period in 2013 at all the observed depths (Fig. 2b) and the variations in soil moisture seemed to have closely followed the variations in the precipitation (Fig. 2a). Because both the air and soil temperatures were below $0^{\circ} \mathrm{C}$ from preceding early November to succeeding early March, the soil moistures immediately after the freezing period (i.e., succeeding late March and early April) was similar to the soil moisture immediately before the freezing period (i.e., preceding October). This phenomenon is known as soil moisture memory (Seneviratne and 
Koster, 2012). Because of a higher amount of precipitation in the summer of 2012, the soil moisture in the succeeding spring (i.e., spring of 2013) was higher than that in the preceding spring (i.e., spring of 2012). It should be particularly noted that the winter snowfall made no contribution to the soil moisture at all. However, after the soil temperature exceeded $0^{\circ} \mathrm{C}$ in late March or early April, snowfall, together with precipitation, can effectively increase the soil moisture. Overall, the variations in soil moisture at shallower depths (i.e., 1, 5, and $10 \mathrm{~cm}$ ) sensitively responded to the rainfall (see Fig. 2a) and the soil moisture at deeper depth (i.e., 20 $\mathrm{cm}$ ) was also respondent to the rainfall but with a lower sensitivity.
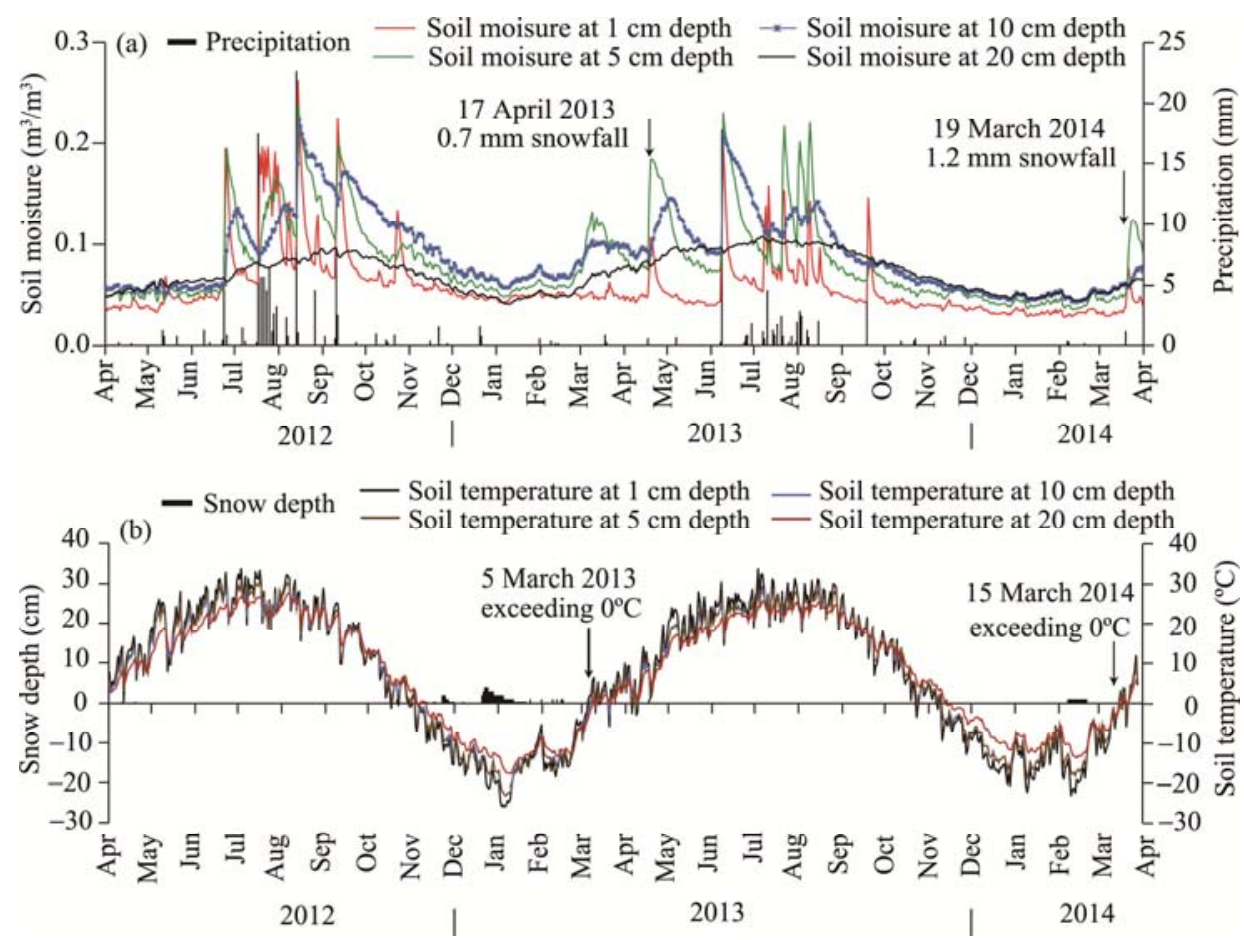

Fig. 2 Temporal variations of soil moisture and precipitation (a) from April of 2012 to March of 2014 in Tsogt-Ovoo valley, and temporal variations of soil temperature and snow depth (b) from April of 2012 to March of 2014 in Tsogt-Ovoo valley

\subsection{Temporal and spatial variations of NDVI}

Vegetation was sparse around the observation site with a vegetation coverage less than $15 \%$ (Ishizuka et al., 2012). Because of the variations in topography and the associated variations in meso-scale hydrological conditions in the valley, the spatial heterogeneity of vegetation coverage could be rather large. Here in this study, we used the NDVI to evaluate the spatial heterogeneity of vegetation coverage at two different spatial scales: (1) a $20 \mathrm{~km} \times 20 \mathrm{~km}$ area centered in the observation site; and (2) a $250 \mathrm{~m} \times 250 \mathrm{~m}$ area corresponding to one pixel of the Terra-MODIS image including the observation site. As shown in Figure 3a, the average spatial NDVI in the 20 $\mathrm{km} \times 20 \mathrm{~km}$ area had drastically increased from late July and reached the maximum value of 0.17 in the early August of 2012. But, no such an increase was observed in 2013. The same patterns were observed for the aboveground biomass that was almost exactly corresponding with the variations in NDVI both in 2012 and 2013. However, the NDVI at the $250 \mathrm{~m} \times 250 \mathrm{~m}$ area did not exhibit any drastic increases both in 2012 and 2013 (Fig. 3b). Keep in mind that the $250 \mathrm{~m} \times 250 \mathrm{~m}$ area corresponding to one pixel of the Terra-MODIS image included the observation site that was situated on the northern slope of the valley (i.e., not in the valley bottom).

Phenologically, vegetation starts to grow after the daily mean air temperature exceeds $5^{\circ} \mathrm{C}$, normally around late March to early April. But, the NDVI did not increase until late June, implying that the amount of soil moisture was insufficient for vegetation growth until late June. 
The best growing time was July-September when the soil moisture was sufficiently recharged by precipitation. For example, the precipitation were $49.4 \mathrm{~mm}$ in July and $31.6 \mathrm{~mm}$ in August of 2012 and the aboveground biomass drastically increased in late July and reached the maximum value of $210 \mathrm{~kg} / \mathrm{hm}^{2}$ in early September (upper panel of Fig. 4). However, both the NDVI and the aboveground biomass did not increase during the best growing time in 2013 (i.e., JulySeptember) simply due to the fact the precipitation was not sufficient to recharge the soil moisture both in July (17.5 mm) and August $(9.5 \mathrm{~mm})$ (lower panel of Fig. 4).
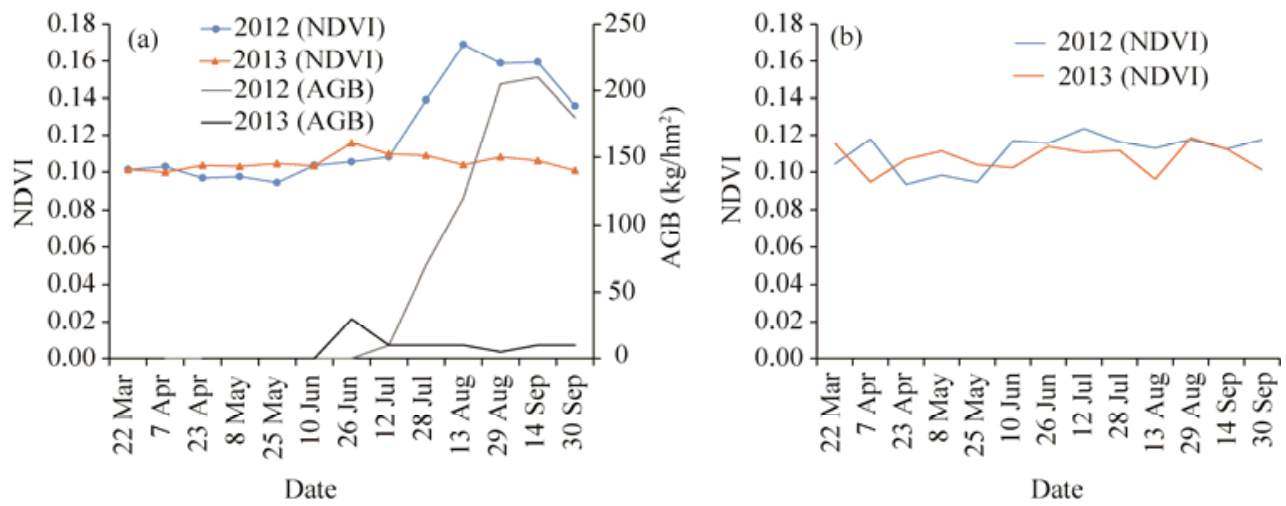

Fig. 3 Seasonal variations in the NDVI between March and September (both in 2012 and 2013) in the 20 $\mathrm{km} \times 20 \mathrm{~km}$ area centered in the observation site and the corresponding aboveground biomass (AGB) at Tsogt-Ovoo valley (a). The NDVI in the $250 \mathrm{~m} \times 250 \mathrm{~m}$ area corresponding to one pixel of the Terra-MODIS image including the observation site (b). The values were obtained by a 16-day composite with 250-m resolution. The day on the $\mathrm{x}$-axis is the initial day of the composite period.

Again, the average spatial NDVI in the $20 \mathrm{~km} \times 20 \mathrm{~km}$ area had drastically increased from late July and reached the maximum value of 0.17 in the early August of 2012. But, no such an increase was observed in 2013. It is quite notable that the NDVI exceeded 0.33 in the valley bottom from 28 July to 28 August of 2012 and the NDVI $(>0.33)$ can be considered to be unexpectedly high for a desert steppe. The unexpectedly high NDVI was primarily resulted from the topography-modulated redistribution of overland flow after relatively heavy precipitation events. Specifically, the slope overland flow can be readily concentrated into the valley bottom, forming a temporal pond (Fig. 5a) or a seasonal wetland (Fig. 5b). It should be stressed here that although the NDVI in July and August of 2012 ( $>0.33$ ) was unexpectedly high in the valley bottom, the NDVI of the same period was rather low in the uplands (see Fig. 3b), suggesting that the heterogeneity of the NDVI is rather large in the desert steppe and that the large heterogeneity was resulted from the variations in topography and the associated variations in meso-scale hydrological conditions.

The aforementioned differences of NDVI (see Figs. 3 and 4), between non-peak growing season (i.e., from 23 April to 8 June) and peak growing season (i.e., from 28 July to 28 August), between the uplands and the valley bottom, and between 2012 and 2013, can be better expressed by plotting the pixel-based NDVI values against the pixel-corresponding altitudes. Figure 6 showed that the altitude did not play any detectable role in the NDVI distribution simply because the relief or altitude difference is not significantly large. In other words, neither orographic precipitation nor environmental lapse rate of temperature had a detectable imprint on the NDVI under the desert steppe climate. Instead, contrast of NDVI between the uplands and the valley bottom was rather striking only during the peak growing season (i.e., from 28 July to 28 August) of 2012. Again, the unexpectedly high NDVI in the valley bottom within the context of a desert steppe climate was primarily resulted from the topography-modulated redistribution of overland flow after relatively heavy precipitation events during the peak growing season of 2012. Once more, the unexpectedly low NDVI in the valley bottom even during the peak growing season of 
2013 was simply due to the fact the growing-season precipitation of 2013 was not sufficient to recharge the soil moisture.

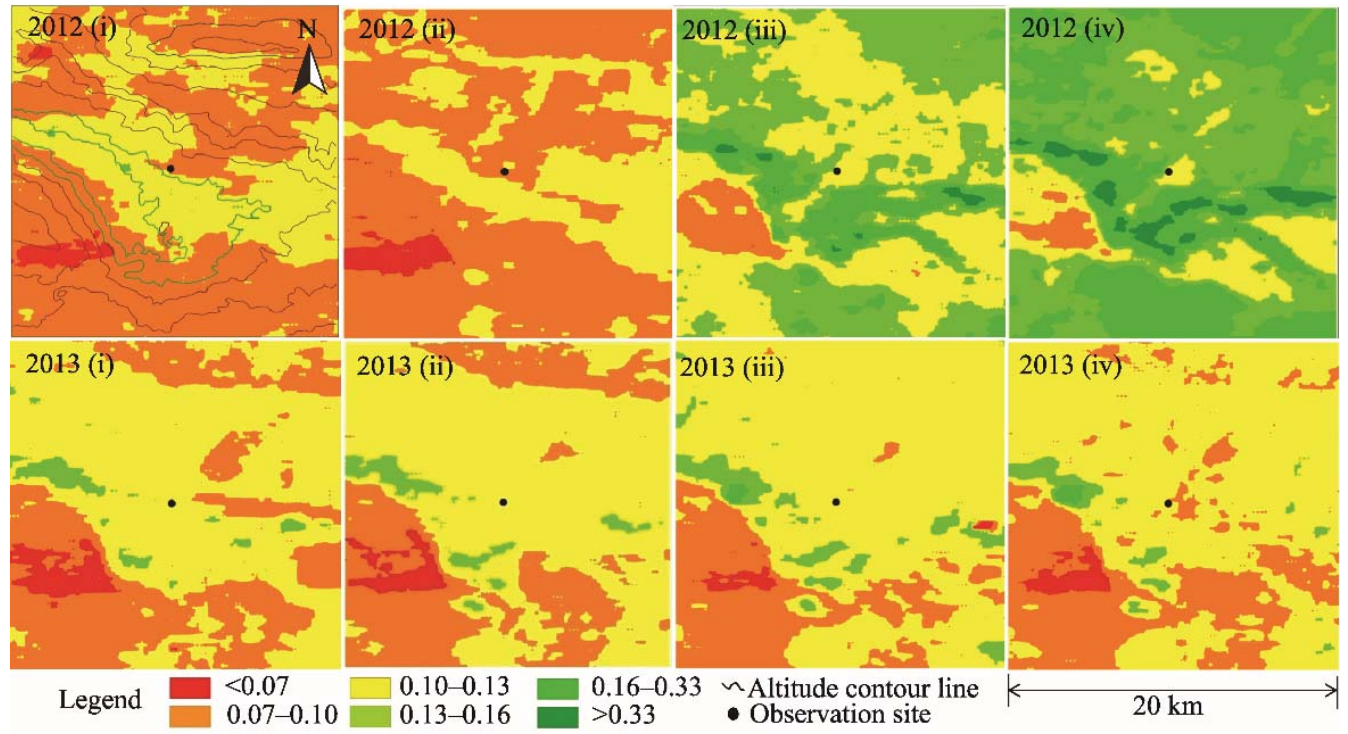

Fig. 4 Temporal and spatial distributions of the NDVI during four different periods from April to August: (i) 23 April to 7 May; (ii) 25 May to 8 June; (iii) 28 July to 12 August; and (iv) 13 August to 28 August. Upper panel: 2012; and lower panel: 2013. Altitude contour lines with 20-m intervals are drawn in the upper-left diagram. The green line in the upper-left diagram is the altitude contour of $1230 \mathrm{~m}$. The observation site is marked by black dots in all of above 8 diagrams.
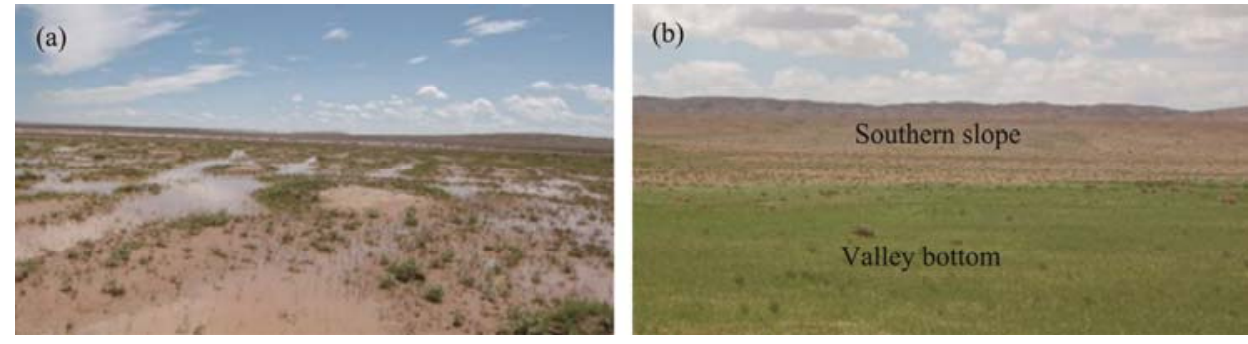

Fig. 5 Photos of the landscape and vegetation in the Tsogt-Ovoo valley: (a) water-storing situation in the valley bottom on 31 July of 2012; and (b) view from the valley bottom to uplands on 1 August of 2012.

To investigate the topographic effects on vegetation coverage, we compared the variations in the vegetation coverage in the valley bottom and in the uplands from 2000 to 2013 using standard deviation (SD). The SD of a 14-year average NDVI maximum (NDVI $\mathrm{max}_{\text {ax }}$ (from 2000 to 2013) unequivocally demonstrated that the SD of $\mathrm{NDVI}_{\max }$ was by far larger in the valley bottom than in the uplands (Fig. 7). Specifically, the SD ranged from 0.05 to 0.18 in the valley bottom, whereas the SD was less than 0.05 in the uplands. This means that the vegetation coverage in the valley bottom has a much greater sensitivity to climate change than that in the uplands and that the elevated sensitivity in the valley bottom was once again resulted from the topography-modulated redistribution of overland flow after relatively heavy precipitation events during the peak growing season. This also implies that the valley bottoms within desert steppe climates are more vulnerable to climatic change although they (i.e., valley bottoms) are more reliable feeding resources for livestock.

The vegetation coverage in the desert steppe zone of Mongolia has much higher variation in comparison with other vegetation zones in the country because of the large-amplitude variations of precipitation (Vandandorj et al., 2015). Our research demonstrated that the topography is very important for vegetation growth at small spatial scales. For example, the unexpectedly high NDVI 
and associated high aboveground biomass were primarily resulted from the topography-modulated redistribution of overland flow after relatively heavy precipitation events. Moreover, the overland flow from the surrounding high terrains was able to carry the eroded fine soils and organic materials (dead vegetation and livestock dung, etc.) down to the valley bottom, effectively increasing the soil fertility for vegetation growth and thus making the valley bottom a primary feeding source of pastoral livestock in Mongolia (Miller and Sheehy, 2008).
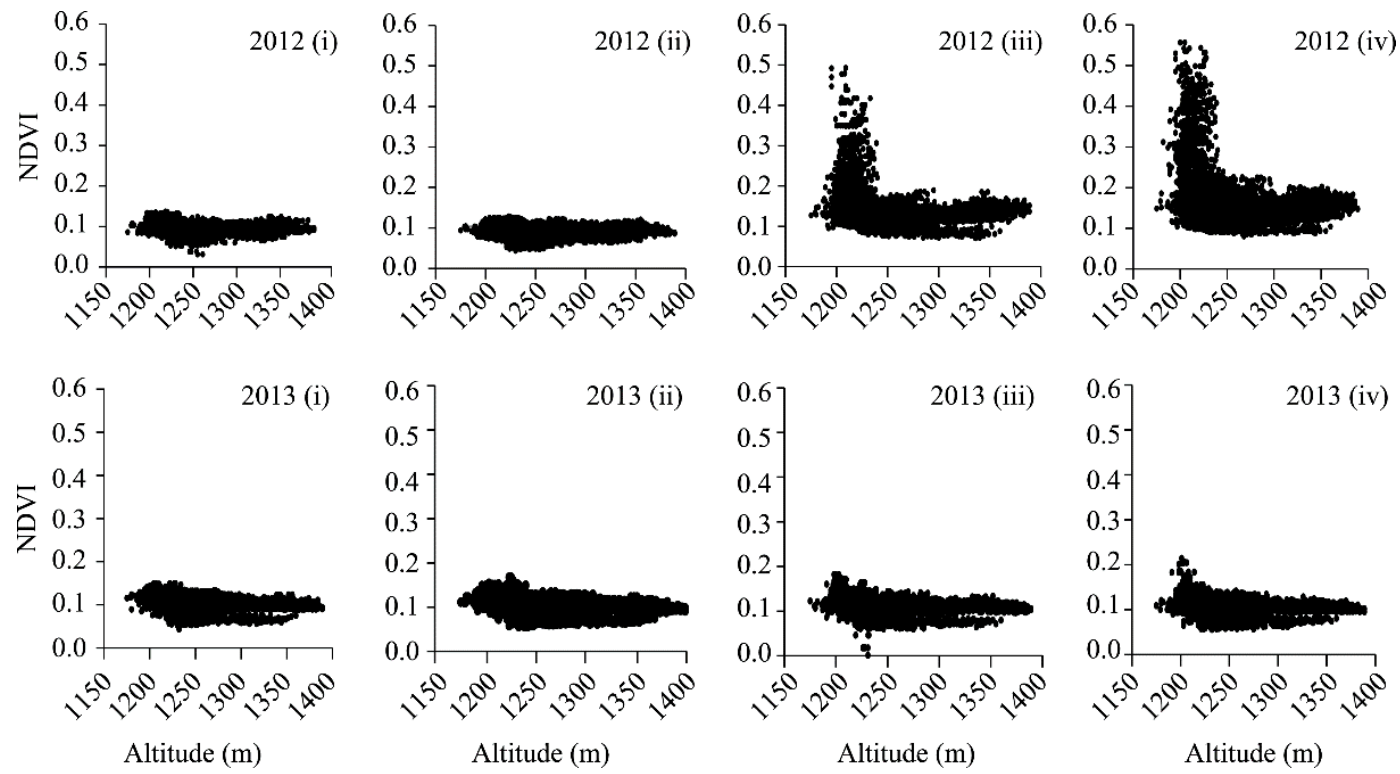

Fig. 6 Relationship between NDVI and altitude during four different periods from April to August: (i) 23 April to 7 May; (ii) 25 May to 8 June; (iii) 28 July to 12 August; and (iv) 13 August to 28 August. Upper panel: 2012; lower panel: 2013; and size: $20 \mathrm{~km} \times 20 \mathrm{~km}$. Each dot represent one pixel $(250 \mathrm{~m} \times 250 \mathrm{~m})$.

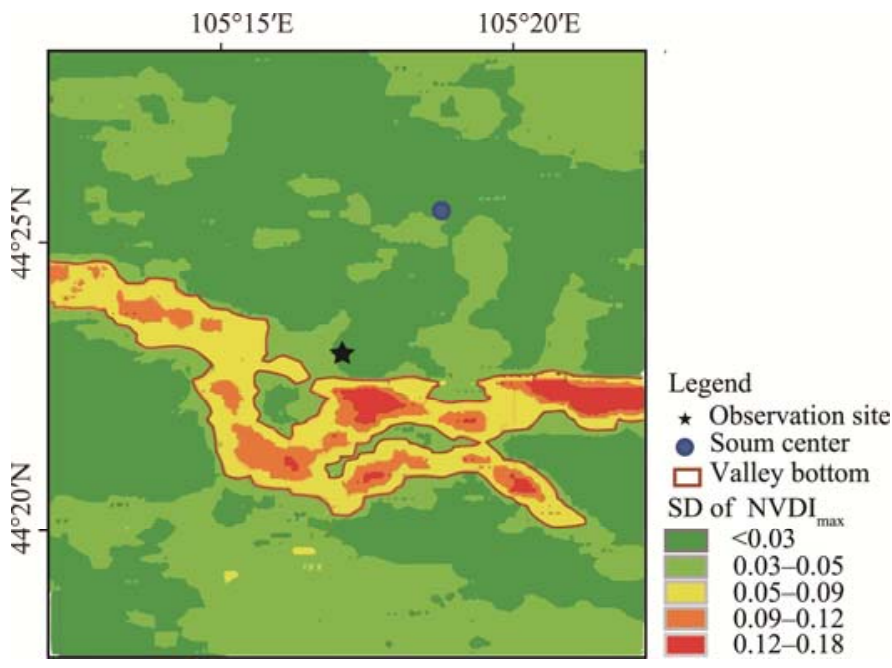

Fig. 7 Standard deviation (SD) of annual maximum NDVI (NDVI $\mathrm{max}$ ) at the Tsogt-Ovoo valley during 20002013. The valley bottom is marked by red lines.

\subsection{A longer-term variation of vegetation coverage}

As aforementioned, the trends in NDVI variations were detected via the nonparametric Mann-Kendall test and the changing rates were evaluated based on Sen's slope. Figure 8 presents the mean NDVI trends and the mean changing rates during the four observing periods from 2000 to 2013: (i) 23 April to 7 May; (ii) 25 May to 8 June; (iii) 28 July to 12 August; and (iv) 13 
August to 28 August. The overall mean NDVI (2000-2013) in the uplands exhibited an increasing trend (i.e., Sen's slope $>0$ ) from 23 April to 12 August and a decreasing trend from 12 August onward (i.e., Sen's slope $<0)$. However, the overall mean NDVI (2000-2013) in the valley bottom increased only during the peak precipitation period from 28 July to 12 August. Our interpretation for the longer-term difference of NDVI between the valley bottom and the uplands is as follow. For the uplands, the NDVI increasing trend was a sensitive response to the precipitation increasing trend from 23 April to 12 August and the decreasing trend after 12 August was most likely caused by persistently-high temperature-resulted soil moisture deficit. For the valley bottom, the drastic jump in NDVI from 28 July to 12 August was most likely an exaggerated response to heavy precipitation of the same time period. The decrease of NDVI in the valley bottom after August was also probably caused by persistently-high temperature-resulted soil moisture deficit.

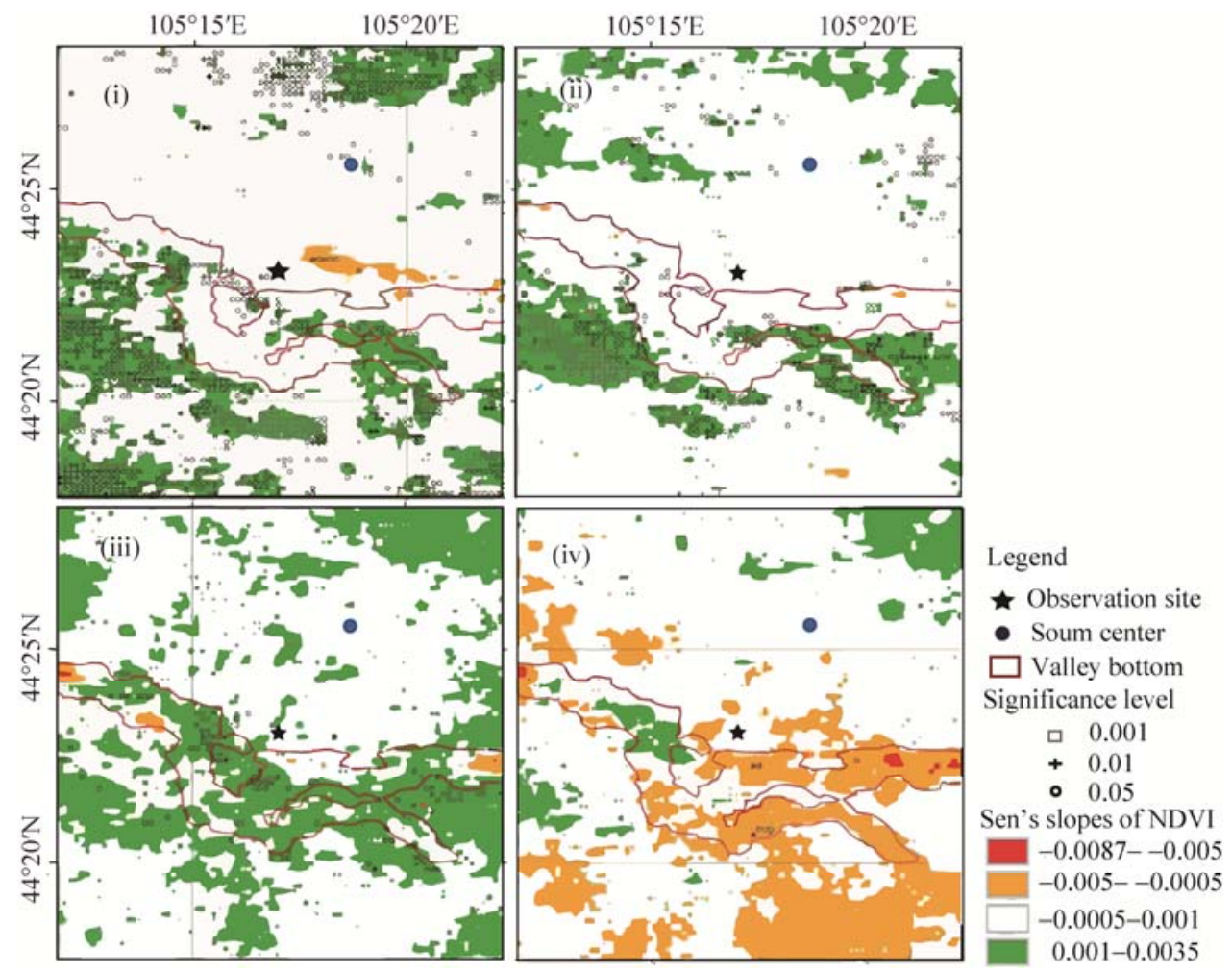

Fig. 8 Sen's slopes of the overall mean NDVI during four observing periods from 2000 to 2013: (i) 23 April to 7 May; (ii) 25 May to 8 June; (iii) 28 July to 12 August; and (iv) 13 August to 28 August

\section{Conclusions}

This study found that the precipitation and the associated soil moisture in July and August are the most important factors affecting vegetation growth in the desert steppe of Mongolia. The winter snowfall made no contribution to the soil moisture simply due to the fact that the winter snow was mostly exhausted by sublimation. However, after the soil temperature exceeded $0^{\circ} \mathrm{C}$ in late March or early April, snowfall, together with precipitation, can effectively increase the soil moisture.

We have also explored the effects of the topography on vegetation growth and the associated aboveground biomass using in-situ observed climate data and Terra-MODIS NDVI data and several conclusions can be drawn. First, the topographic features at small spatial scales are very important for vegetation growth in the desert steppe although the summer precipitation is the constraining factor. Second, the unexpectedly high NDVI (up to 0.56), as well as the aboveground biomass, in the valley bottom under the desert steppe climate is primarily resulted from the 
topography-modulated redistribution of overland flow after relatively heavy precipitation events during the growing season. Third, rather large standard deviation (SD) of the annual maximum NDVI $\left(\mathrm{NDVI}_{\max }\right)$ in the valley bottom in response to rather variable precipitation implies that the valley bottoms within desert steppe climates are more vulnerable to climatic change although they (i.e., valley bottoms) are more reliable feeding resources for livestock.

\section{Acknowledgements}

This research was financially supported by the Japan Society for the Promotion of Science RONPAKU Program (MECS-11319), a Budget Request of Tottori University, and sponsored by special coordination funds from the Ministry of Education, Culture, Sports, Science and Technology of the Japan.

\section{References}

Cheng Y, Tsubo M, Ito T Y, et al. 2011. Impact of rainfall variability and grazing pressure on plant diversity in Mongolian grasslands. Journal of Arid Environments, 75(5): 471-476.

Chuluun T, Ojima D. 2002. Land use change and carbon cycle in arid and semi-arid lands of East and Central Asia. Science in China (Series C), 45(Suppl.): 48-54.

Dagvadorj D, Batjargal Z, Natsagdorj L. 2014. Mongolia second Assessment Report on Climate Change-2014. Ministry of Environment and Green Development of Mongolia. Ulaanbaatar, Mongolia. 37-52.

Fensholt R, Langanke T, Rasmussen K, et al. 2012. Greenness in semi-arid areas across the globe 1981-2007-an earth observing satellite based analysis of trends and drivers. Remote Sensing of Environment, 121: 144-158.

Guo L H, Wu S H, Zhao D S, et al. 2014. NDVI-based vegetation change in Inner Mongolia from 1982 to 2006 and its relationship to climate at the biome scale. Advances in Meteorology, 2014: 692068.

Ignatavičius G, Sinkevičius S, Ložytė A. 2013. Effects of grassland management on plant communities. Ekologija, 59(2): 99110.

Ishizuka M, Mikami M, Yamada Y, et al. 2012. Does ground surface soil aggregation affect transition of the wind speed threshold for saltation and dust emission?. Scientific Online Letters on the Atmosphere Sola, 8: 129-132.

Iwasaki H. 2006. Impact of interannual variability of meteorological parameters on vegetation activity over Mongolia. Journal of the Meteorological Society of Japan Series II, 84(4): 745-762.

Jambaajamts B. 1989. Climate of Mongolia. Ulaanbaatar: Ulsiin Hevlel Publishers. (in Mongolian)

Jarlan L, Driouech F, Tourre Y, et al. 2014. Spatio-temporal variability of vegetation cover over Morocco (1982-2008): linkages with large scale climate and predictability. International Journal of Climatology, 34(4): 1245-1261.

Johnson D A, Sheehy D P, Miller D, et al. 2006. Mongolian rangelands in transition. Sécheresse, 17(1-2): $133-141$.

Li S G, Asanuma J, Kotani A, et al. 2007. Evapotranspiration from a Mongolian steppe under grazing and its environmental constraints. Journal of Hydrology, 333(1): 133-143.

Li Z Q, Guo X L. 2012. Detecting climate effects on vegetation in northern mixed prairie using NOAA AVHRR 1-km time-series NDVI data. Remote Sensing, 4(1): 120-134.

Li Z Q, Guo X L. 2014. Topographic effects on vegetation biomass in semiarid mixed grassland under climate change using AVHRR NDVI data. British Journal of Environment and Climate Change, 4(2): 229-242.

Lu L, Li X, Veroustraete F, et al. 2009. Analysing the forcing mechanisms for net primary productivity changes in the Heihe river basin, north-west China. International Journal of Remote Sensing, 30(3): 793-816.

Ma W H, Fang J Y, Yang Y H, et al. 2010. Biomass carbon stocks and their changes in northern China's grasslands during 1982-2006. Science China Life Sciences, 53(7): 841-850.

Mayes M T, Mustard J F, Melillo J M. 2015. Forest cover change in Miombo woodlands: modeling land cover of African dry tropical forests with linear spectral mixture analysis. Remote Sensing of Environment, 165: 203-215.

Miller D, Sheehy D. 2008. The relevance of Owen Lattimore's writings for nomadic pastoralism research and development in inner Asia. Nomadic Peoples, 12(2): 103-115.

Miyazaki S, Yasunari T, Miyamoto T, et al. 2004. Agrometeorological conditions of grassland vegetation in central Mongolia and their impact for leaf area growth. Journal of Geophysical Research, 109(D22): D22106.

Munkhtsetseg E, Kimura R, Wang J, et al. 2007. Pasture yield response to precipitation and high temperature in Mongolia. Journal of Arid Environments, 70(1): 94-110.

Ni J. 2003. Plant functional types and climate along a precipitation gradient in temperate grasslands, north-east China and 
south-east Mongolia. Journal of Arid Environments, 53(4): 501-516.

Pettorelli N, Vik J O, Mysterud A, et al. 2005. Using the satellite-derived NDVI to assess ecological responses to environmental change. Trends in Ecology \& Evolution, 20(9): 503-510.

Ridd M K. 1995. Exploring a V-I-S (vegetation-impervious surface-soil) model for urban ecosystem analysis through remote sensing: comparative anatomy for cities. International Journal of Remote Sensing, 16(12): 2165-2185.

Saizen I, Maekawa A, Yamamura N. 2010. Spatial analysis of time-series changes in livestock distribution by detection of local spatial associations in Mongolia. Applied Geography, 30(4): 639-649.

Sayemuzzaman M, Jha M K. 2014. Seasonal and annual precipitation time series trend analysis in North Carolina, United States. Atmospheric Research, 137: 183-194.

Seneviratne S I, Koster R D. 2012. A revised framework for analyzing soil moisture memory in climate data: derivation and interpretation. Journal of Hydrometeorology, 13(1): 404-412.

Stumpp M, Wesche K, Retzer V, et al. 2005. Impact of grazing livestock and distance from water source on soil fertility in southern Mongolia. Mountain Research and Development, 25(3): 244-251.

Vandandorj S, Gantsetseg B, Boldgiv B. 2015. Spatial and temporal variability in vegetation cover of Mongolia and its implications. Journal of Arid Land, 7(4): 450-461.

Wang J, Price K P, Rich P M. 2001. Spatial patterns of NDVI in response to precipitation and temperature in the central Great Plains. International Journal of Remote Sensing, 22(18): 3827-3844.

Wang J, Rich P M, Price K P. 2003. Temporal responses of NDVI to precipitation and temperature in the central Great Plains, USA. International Journal of Remote Sensing, 24(11): 2345-2364.

Wang X M, Chen F H, Dong Z B, et al. 2006. The relative role of climatic and human factors in desertification in semiarid China. Global Environmental Change, 16(1): 48-57.

Weng Q H, Lu D S. 2009. Landscape as a continuum: an examination of the urban landscape structures and dynamics of Indianapolis City, 1991-2000, by using satellite images. International Journal of Remote Sensing, 30(10): $2547-2577$.

Yamanaka T, Kaihotsu I, Oyunbaatar D, et al. 2007. Summertime soil hydrological cycle and surface energy balance on the Mongolian steppe. Journal of Arid Environments, 69(1): 65-79.

Yin H, Udelhoven T, Fensholt R, et al. 2012. How normalized difference vegetation index (NDVI) trends from advanced very high resolution radiometer (AVHRR) and système probatoire d'Observation de la Terre VEGETATION (SPOT VGT) time series differ in agricultural areas: an Inner Mongolian case study. Remote Sensing, 4(11): 3364-3389.

Yu F F, Price K P, Ellis J, et al. 2003. Response of seasonal vegetation development to climatic variations in eastern central Asia. Remote Sensing of Environment, 87(1): 42-54.

Yue W Z, Xu J H, Wu J W, et al. 2006. Remote sensing of spatial patterns of urban renewal using linear spectral mixture analysis: a case of central urban area of Shanghai (1997-2000). Chinese Science Bulletin, 51(8): 977-986.

Yunatov A A. 1976. Fundamental Characteristics of the Vegetation of Mongolian People's Republic. Ulaanbaatar: Mongolian Academy of Science. (in Mongolian)

Zhang J Y, Dong W J, Fu C B, et al. 2003. The influence of vegetation cover on summer precipitation in China: a statistical analysis of NDVI and climate data. Advances in Atmospheric Sciences, 20(6): 1002-1006.

Zhang X Y, Hu Y F, Zhuang D F, et al. 2009. NDVI spatial pattern and its differentiation on the Mongolian Plateau. Journal of Geographical Sciences, 19(4): 403-415.

Zhang Y S, Munkhtsetseg E, Kadota T, et al. 2005. An observational study of ecohydrology of a sparse grassland at the edge of the Eurasian cryosphere in Mongolia. Journal of Geophysical Research, 110(D14): D14103.

Zhao X, Hu H F, Shen H H, et al. 2015. Satellite-indicated long-term vegetation changes and their drivers on the Mongolian Plateau. Landscape Ecology, 30(9): 1599-1611.

Zhou L, Kaufmann R K, Tian Y, et al. 2003. Relation between interannual variations in satellite measures of northern forest greenness and climate between 1982 and 1999. Journal of Geophysical Research, 108(D1): ACL 3-1-ACL 3-16.

Zhu Z C, Bi J, Pan Y Z, et al. 2013. Global data sets of vegetation leaf area index (LAI) 3g and fraction of photosynthetically active radiation (FPAR) $3 \mathrm{~g}$ derived from global inventory modeling and mapping studies (GIMMS) normalized difference vegetation index (NDVI3g) for the period 1981 to 2011. Remote Sensing, 5(2): 927-948. 